Karoliina Vuola (MSc) graduated as a physics teacher year 2018. She has been acting as a physics and mathematics teacher in an upper secondary school in Finland. At present, MSc Vuola is preparing her PhD dissertation in the Department of Physics in the University of Helsinki.

Maija Nousiainen (PhD) works as a university lecturer in the Department of Physics in the University of Helsinki. Her research activities concentrate on Physics Education Research, especially on pre-service physics teachers' knowledge organization methods.

\title{
Physics knowledge justification: an analysis framework to examine physics content knowledge
}

\begin{abstract}
Argumentation and knowledge justification have been noted as important skills to be learned in secondary and tertiary level of education. These skills are especially crucial in teaching and learning physics because physics knowledge is normative and has hierarchical structure. The purpose of this article is two-fold. First, we propose a framework to analyze pre-service physics teachers' knowledge justification. Second, we show how this framework can be used to examine pre-service physics teachers' knowledge justification in the context of quantum physics. The sample consists of 68 knowledge justification schemes on four quantum phenomena ( $N=17$ participants who all produced four schemes). The proposed framework discusses conceptual, relational and strategic knowledge presented in knowledge justification schemes. The results show that analysis framework reveal significant differences between pre-service teachers' knowledge justification. We conclude that there is need and room for such practical tools, which help future teachers to organize and consider their own knowledge.
\end{abstract}

\section{INTRODUCTION}

Understanding of scientific concepts, scientific method and reasoning required for decision-making in one's personal life and society has been named one of the $21^{\text {st }}$ century skills (Turiman, Omar, Daud, \& Osman, 2012). Understanding the nature of scientific knowledge and argumentation skills can be promoted by emphasizing them in instruction during high school and university studies (Fischer et al., 2014; Holmes, Wieman, \& Bonn, 2015; Rapanta, Garcia-Mila, \& Gilabert, 2013). This broad aim for science education is here inspected from the viewpoint of physics teacher education and, especially, we explore pre-service physics teachers' knowledge justification. Physics teachers' skills and 
abilities in providing coherent and sound physics arguments in their teaching affect their students' conceptions and understanding of physics knowledge. Therefore, it is essential to ensure physics teachers' good argumentation skills in communicating their teaching.

Physics knowledge is normative and has hierarchical structure in which physics concepts are the basic structural elements. A recent view on knowledge as a system suggests that different knowledge elements acquire their meaning as part of that system (Kokkonen, 2017; Koponen \& Kokkonen, 2014). This forms a conceptual system, where relational structures between concepts are central (Koponen \& Kokkonen, 2014). Such relations are physics laws. The nature of physics knowledge described in this way, has been identified as one central difficulty in learning physics. Therefore, in teaching and learning physics we must underline logical, coherent, analytical and critical thinking, and argumentation. These are indisputable parts of physics as discipline (Sandoval \& Millwood, 2007).

Educational environment does not usually support pre-service teachers' engagement into critical thinking process but it can be enhanced with careful practice (c.f. Holmes, Wieman \& Bonn, 2015). Schools and educators play a key role when it comes to learning critical thinking and reasoning. Therefore, teacher educators need suitable and practical tools to enhance pre-service teachers' formation of such knowledge. Different graphical tools to facilitate pre-service teachers' knowledge organization have been successfully implemented in physics teacher education (Nousiainen, 2013; Nousiainen, 2017, Nousiainen, Hyytinen, Palmgren \& Toom, 2019). However, these tools need closer inspection in terms of their possibility to support pre-service teachers' knowledge justification.

The aim of this study is to gain deeper understanding on learning reasoning, argument construction and knowledge justification. From practical point of view, the aim of this research is also to develop learning solutions to support pre-service physics teachers' skills in substantiating physics knowledge. As practical instructional solution to enhance knowledge justification skills, we have used knowledge justification schemes, KJS (Nousiainen, 2017) as a learning tool and as a data collection tool. The research questions have been set as

1. What is a suitable analysis framework to inspect students KJSs?

2. What kind of variation in physics knowledge justification can be found between students' KJSs?

We propose a hypothesis that variation between students is significant and it can be detected by using the new analysis schema, which is based on inspection of three epistemic knowledge dimensions; being conceptual, relational and strategic knowledge. The new analysis framework is presented and its usability to examine physics knowledge justification is justified in what follows.

\section{AIMS AND NEEDS OF ARGUMENTATION IN PHYSICS}

An argument consists of a premise, an assumption or data, a method reasoning or a warrant and a concluding claim (see e.g. Toulmin, 2003). Argumentation usually refers to the use of arguments in which also rhetoric plays a central role in convincing the opponent. This study concentrates only on argumentation which emphasizes knowledge justification and knowledge claims supported by evidence and reasoning (Shehab \& Nussbaum, 2015; Toulmin, 2003). When assessing arguments from this point of view, we concentrate on the credibility, relevance, logic and harmony of the claim and its warrant, and the clarity of concepts. Argument fails if any of its part (premise, warrant or claim) is irrelevant, unclear, false or clearly unbelievable. For example, over-rigorous interpretation, generalization from anecdotes or from single cases, correlation explained as causality, feint, leaning on tradition, general opinion, popularity or authority (Hyytinen, Löfström, \& Lindblom-Ylänne, 2017). The general ideas of argumentation of being logical chain of justified knowledge claims can be easily contextualized into any discipline. For a becoming physics teacher it means ability to clearly and logically justify physics knowledge, which reflects his/hers coherent and well-ordered subject matter knowledge (Nousiainen, 2017, see also Lachner \& Nückles, 2016). 
Physics instruction in an advanced level is often concentrated on well-established laws, models, and theories, which are regarded as facts with no need to question where they come from (Mäntylä \& Hämäläinen, 2015; Sandoval \& Millwood, 2007). This might induce a shortage of epistemic understanding if students do not have to think how these established concepts are substantiated. In physics, experiments and models build connections between physics concepts and tie them together. It has been pointed out that even after basic and intermediate physics studies, physics students (including pre-service physics teachers) do possess relevant knowledge, but it consists of a collection of fragmented pieces (Mäntylä \& Nousiainen, 2014). Pre-service physics teachers seem to lack a coherent view of the physics knowledge system, and therefore, they need support in developing their overall understanding of physics content knowledge.

\section{PHYSICS KNOWLEDGE AND KNOWLEDGE JUSTIFICATION IN PHYSICS}

Physics concepts are terms and names, which build the physics lexicon; they are basic structural elements, which outline physics knowledge. A recent view on knowledge as a system emphasizes that different knowledge elements acquire their meaning as part of that system (Kokkonen, 2017; Koponen \& Kokkonen, 2014). This view is supported by the notion of the role of relations and relational knowledge in building the meaning of concepts (Goldwater \& Schalk, 2016; Halford, Wilson, \& Phillips, 2010). In physics knowing concepts, their definitions and ways they are applied in different contexts or conditions, form a basis for connecting concepts together.

The most obvious attempt to explore the relational conceptual connections is focusing on concepts, and on how relationships between the concepts emerge on different contexts they are explicated. These conceptual relations eventually forms a lexicon of concepts, where connection between them derive from contextualized instances how concepts are used and situations are named (Kuhn, 2000). Here, we concentrate on exact relations between physics concepts, namely physics laws.

Traditionally, physics knowledge is built through experiments and observations, starting from individual cases to laws, models, and theories that are more general. Thus, there is an inherent dependence between experiments and physics theory. The aim of experiments in physics instruction is usually to verify predictions and to show the phenomena (Mäntylä \& Hämäläinen, 2015). Laboratory experiments give us measured data of quantitative dependence between variables (quantities). This dependence can be formulated as physics law. Besides experiments, models and modeling are essential in building physics knowledge. Real physics phenomena can be represented by using models, which help us to interpret and understand the phenomena more deeply. The main aim of modeling is controllability and calculability: model simplifies and idealizes the phenomena. Models can help us to simplify the process and dependence or clarify making predictions (Halloun, 2007; Koponen, 2007; Kosso, 2009). There are different ways to use models in physics instruction to support concept formation. Here we introduce four most obvious manners to apply models in teaching and learning physics

1. Model describing a real situation. Idealizes the target and removes unimportant details. For example, a uniform electric field inside a capacitor.

2.Model defining concepts. For example, a uniform electric field and its different representations (electric field line model, equipotential surfaces, field vectors, etc.)

3.Defining theoretical model. For example, Gauss law describes the amount of sources (electric charges) and their relation to electric field.

4.Data model. Data model is an ideal way to represent data. This can be a dependence between measured quantities, e.g. linear dependence, .

Physics knowledge is complex and it has many components. However, we can identify two different types of physics laws, which are experimental law and theoretical law. An experimental law is justified based on experimental observations. Experimental process consists of the experimental setup, exact measurements and the data model emerging from measurement. A theoretical law combines previous laws together so that they form a new model, which explains a new phenomenon. We in- 
spect here these two types of physics law as separate categories in order to keep the situation simple enough. This is a limited view on physics knowledge since it lacks the interplay between models and experiments. The dependencies between experiments and models is here inspected in the epistemic analysis (see next section). An example of an experimental law is e.g. relation, which tells the energy needed to detach electrons in photoelectric effect. Millikan's experiment produces results which provide evidence for Einstein's prediction (Millikan, 1916). An example of a theoretical law is Compton's relation, which explicates the wavelength difference in x-ray scattering (Compton 1923a; 1923b).

\section{EPISTEMIC ANALYSIS ON PHYSICS KNOWLEDGE}

Physics content knowledge to be learned includes a collection of physics concepts (quantities), laws, general principles, models and experiments. It is of importance to understand how these different pieces are connected to each other and how they can be substantiated (see Nousiainen et al., 2019). Experiments and models create new relational connections between concepts. Therefore, in what follows, we focus our epistemic analysis into concepts, relations and models and experiments. Physics content knowledge can be approached by dividing it into three subcategories (for more details, see Nousiainen et al., 2019):

1. Conceptual knowledge (C) refers to the ability to identify and define relevant physics concepts and to reflect on their applicability. In this paper, we discuss conceptual knowledge only as far as it is declarative conceptual knowledge about concepts and terms, such as "an electron" or "wavelength" (cf. Lachner \& Nückles, 2015; Lachner \& Nückles, 2016; Shavelson, 2010). In what follows, conceptual knowledge always refers to declarative knowledge.

2. Relational knowledge (R) about relations between concepts. Relational knowledge refers to the ability to identify how concepts are related to each other, how concepts and their relations are defined or described by models and what the forms and limitations are of such relations or models. Relations and relational knowledge are essential for understanding analogies, explanations, learning concepts, proposing justifications, and problem solving (Halford et al., 2010). For example, "quantization of energy E = hf" presents a relation between a photon's frequency and energy.

3. Strategic knowledge (S) refers to epistemic strategies on how concepts and relations between concepts are formed. In this context, strategic knowledge means knowledge of experimental procedures, and reflection on their restrictions or limitations. Strategic dimension thus assesses how students apply the two other types of knowledge by providing an experimental procedure (Nousiainen, 2013; Shavelson, 2010), for example, "an interference pattern emerges in a double-slit experiment”.

\section{PHYSICS KNOWLEDGE JUSTIFICATION REPRESENTED AS SCHEMES}

Knowledge justification scheme is a tool to study argumentation. The scheme is a graph, where each node represents one argumentative move such as a motive for the research, objective, main conclusion, counterargument, support or implication. The chain of reasoning is represented by links between numbered nodes (argumentative moves) (Nousiainen 2017; see also Toulmin, 1958/2003). The processes generating new knowledge are different in experimental and theoretical laws. Therefore, the way to justify them is also different. Justification of physics' knowledge can be concretized and explicated through these justification schemes (Fischer et al., 2014; Nousiainen, 2017).

\section{METHODOLOGY}

\section{Context}

In Finland, physics subject teachers usually teach 13 to 19-year-olds in grades 7-9 in comprehensive school and grades 10-12 in upper secondary school. Physics teachers complete an academic five-year master's level program $(180+120$ credits). Students who have physics as a major subject have 25 credits orientation studies, 160 credits physics, 60 credits another teaching subject (usually math- 
ematics or chemistry), 15 credits optional physics and 60 credits compulsory pedagogical studies. Physics teachers who have physics as a minor subject complete 60 credits of physics and often have mathematics or chemistry as a major. To get a formal physics teacher qualification, students need to complete the pedagogical studies, which are organized by the Faculty of Education. These studies consist of general pedagogy, pedagogical content knowledge, a pedagogical thesis and teaching practice in authentic school settings. Physics studies are organized by the Faculty of Science and consist of lecture courses, mathematical exercises, seminars, research studies, laboratory experiments and demonstrations.

\section{Participants}

The study was carried out at a large research-intensive university in Finland. The participants of this study were pre-service physics teachers $(\mathrm{N}=17)$ who were on $3^{\text {rd }}$ or $4^{\text {th }}$ year in their studies. The participants had already passed the basic level physics courses including mechanics, electromagnetism, introductory quantum physics, laboratory and method courses on mathematics, coding and experimental work. These courses are same for all physics majors and minors. We refer to participants as students from here onwards.

\section{Data collection}

The data was collected as a part of a physics teacher preparation course, an obligatory intermediate level five-credit university course Physics Concept Formation II, which focuses on organization of physics content knowledge. The context in this study was introductory quantum physics but the same setup could have been tested in any other physics context as well.

The course consisted of lectures and two types of assignments: knowledge justification schemes and didactical schemes. Students were assigned a physics topic and a research article on it. Students analyzed the form and structure of scientific reasoning presented in the article and produced a knowledge justification scheme based on the article. After lecture discussions on these schemes and the topic, students produced a didactical scheme on the same topic. In didactical scheme, students reorganized the topic's contents for teaching purposes (for more details on the assignments, see Nousiainen, 2017). The participants were familiar with the knowledge organization tasks because they had attended the previous course, which also utilized same kinds of assignments. The research material was collected in the form of written knowledge justification schemes. The course assignments for experimental and theoretical physics law knowledge justification schemes were presented to students as follows. To scaffold students' knowledge processing, we offered two templates (see Fig. 1 and 2) for knowledge justification schemes. The templates represent one possible organization and order of the argumentative moves but students were free to modify these templates to fit their own representation.

Argumentative moves for an experimental law of physics are (see also Figure 1)

1. Motive and object. Why is this experiment conducted and what is expected from it?

2. Previous theory. What is already known?

3. Phenomena. What kinds of phenomena are relevant to the task?

4. Experiment and measurements. What are the experimental setup, measurements and results?

5. Data model. What exact relation is found? What does it describe?

6. Conclusion: experimental law. What is the most important result or model?

7. Validity. What are the limitations or counterarguments?

8. Implication: new theory. What is the meaning of the new law in a broader context? 


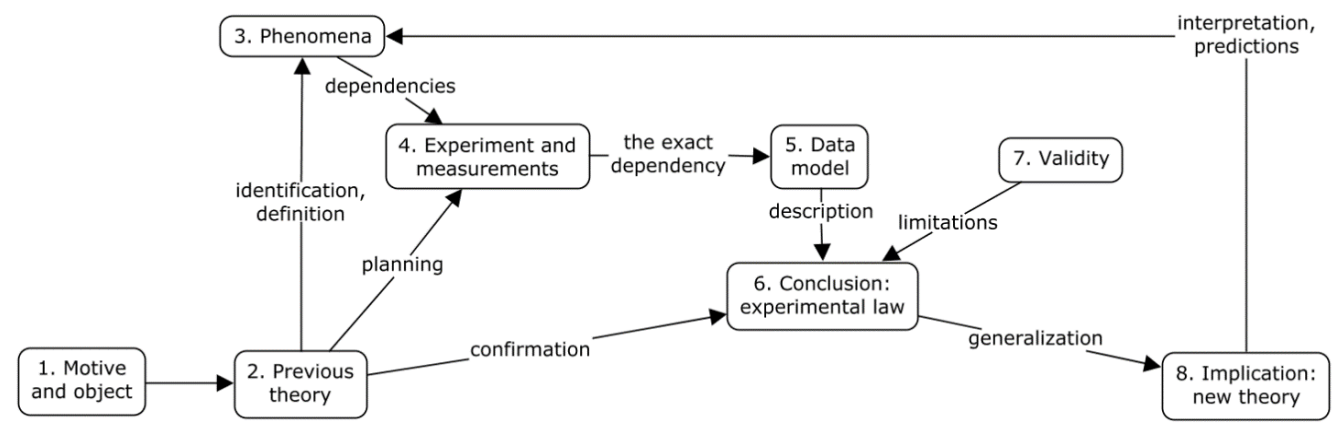

Figure 1. KJS for an experimental law of physics.

Argumentative moves for a theoretical law of physics are (see also Figure 2)

1. Motive and object. Why is new theory needed?

2. Forming theory. What does the new theory want to explain?

3. Previous theory. What is already known?

4. Phenomena. What kind of phenomena are relevant to the task?

5. Model. What does the model describe and what are its predictions?

6. Unexplained part of phenomena. What remains unexplained when using only previous models?

7. Conclusion: new model. What is the most important result?

8. Validity. What are the limitations or counterarguments?

9. Implication: new theory. What is the meaning of the new law in a broader context? 10.

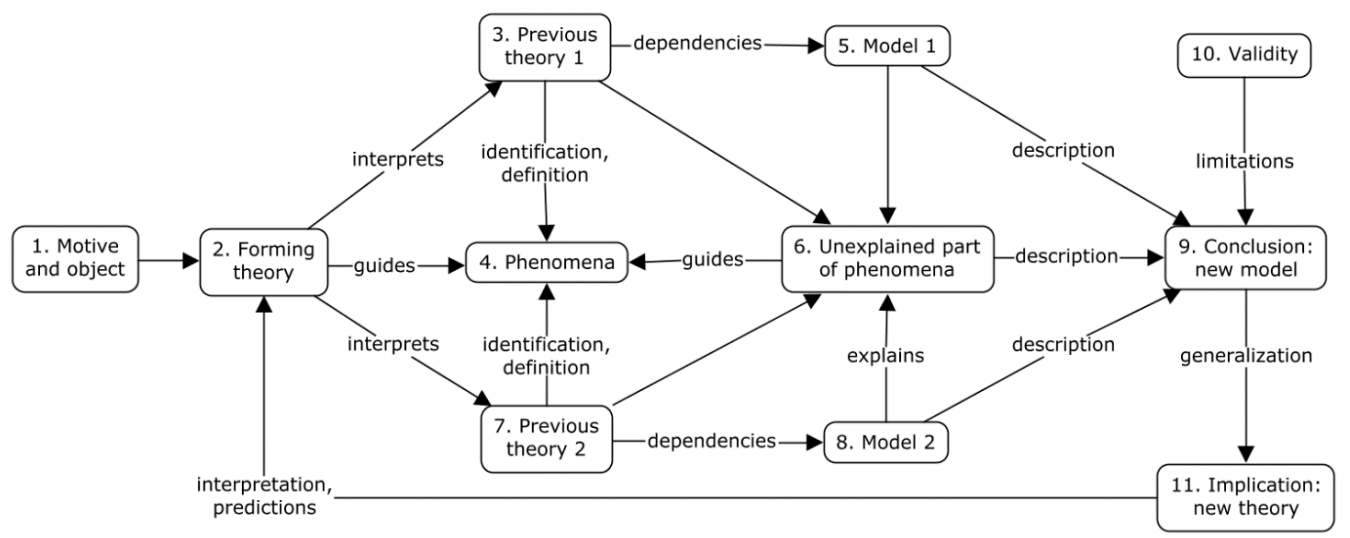

Figure 2. KJS for a theoretical law of physics.

All the students volunteered to participate in the study and gave their informed consent. Students were informed that their course assignments were anonymized for the study and their participation in the study would not have any influence on their grades. Students got no incentive for participating. 

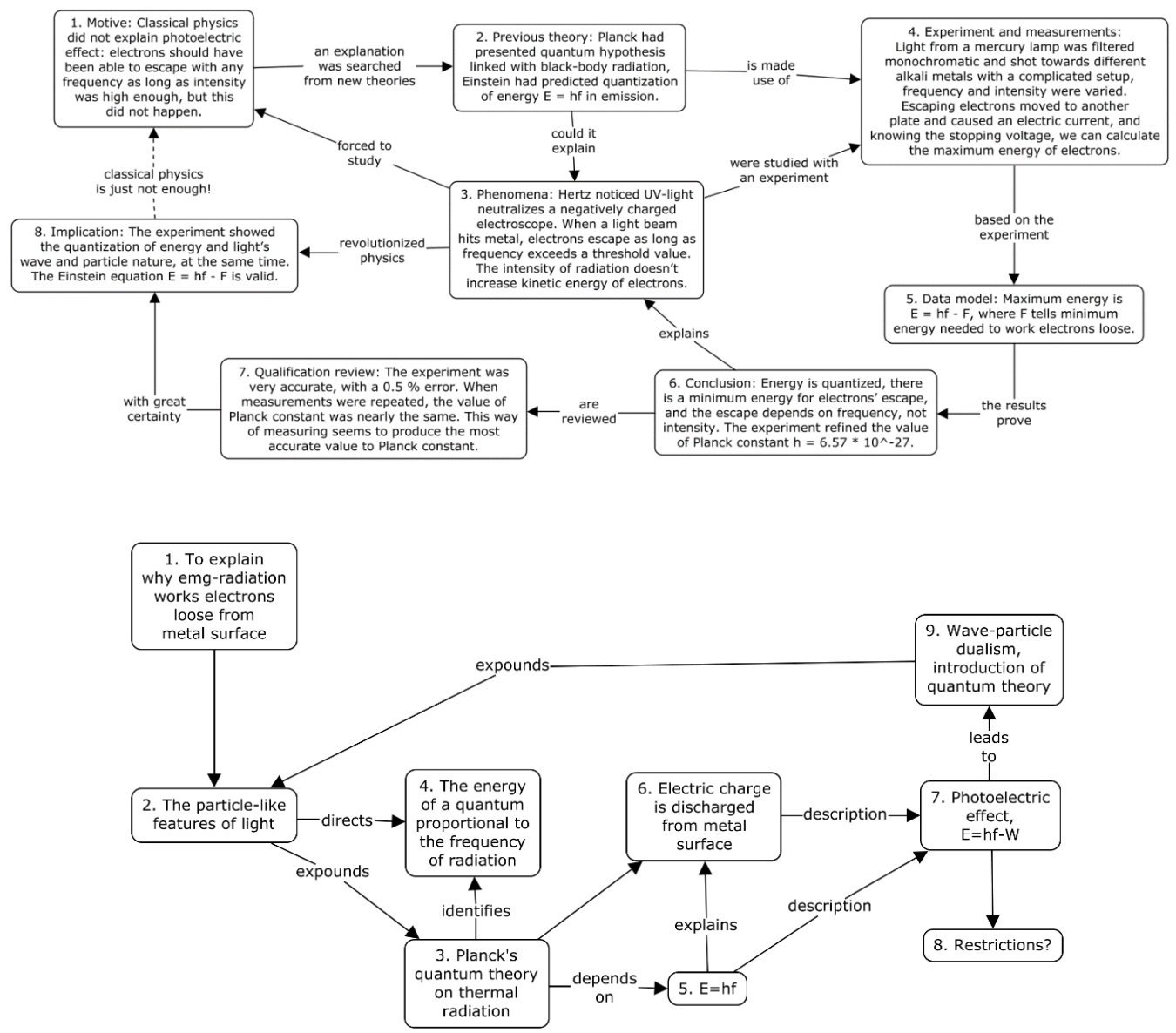

Figure 3. Two examples of a student's KJS on photoelectric effect (KJS 1; upper from student 1, lower from student 6).

\section{Analysis method}

In preparing KJSs, students first read an authentic or a didactic research article, identified its argumentative moves and essential physics contents related to them and based on that, produced each their own knowledge justification scheme on the given subject (two examples illustrated in Fig. 3). Each student produced four KJSs. The topics and their source articles were

1. Photoelectric effect (Millikan, 1916),

2. Compton effect (Compton, 1923a; Compton, 1923b),

3. Double-slit experiment for single photons (Rueckner \& Titcomb, 1996) and

4. Double-slit experiment for electrons (Hobson, 2012).

In these articles, Millikan (1916) provide experimentally evidence for Einstein's theoretical prediction of photoelectric effect. Compton (1923a; 1923b) offers a theoretical prediction of x-ray scattering and experimental evidence for it. Ruekner and Titcomb (1996) present a lecture demonstration of the 
double-slit experiment for single photons. Hobson (2012) discusses the double-slit experiment for single electrons compared to photons, and reflects which one is more fundamental model for electrons and photons, particle or field model.

To answer the research question, mixed methods research was used. All research material went through qualitative content analysis followed by quantitative analysis. Physics content knowledge presented in the KJS was inspected node by node. Nodes were analyzed following criteria for conceptual (C), relational (R) and strategic knowledge (S). Each dimension (C, R and S) was divided into two subcategories: (1) identification and definition of knowledge and (2) condition for using knowledge. The criteria are explicated detailed in tables 1-3.

Each node in a KJS was scored in a scale from o to 2 by criteria introduced below. Score o means there is no relevant or properly explained physics knowledge in the node. Score 1 means there is something relevant physics knowledge but the explanation is inconsistent, inadequate or unclear. Score 2 means the presented physics knowledge is relevant and consistent. The scoring highlights strengths, not weaknesses in students' knowledge: it reveals if there is any relevant physics knowledge presented. Whether the physics knowledge student justified and presented is sufficient or if there is something unnecessary is ignored. Figure 3 shows two examples of students' KJSs on photoelectric effect and tables A1 and A2 their respective scores (see Appendix A).

Different KJSs can contain a different number of nodes in the graphical representation. To make different KJSs comparable, the scores were summed up and normalized. Average scores were calculated for each student's four KJSs and all KJSs, as well. The scores were also compared with each other.

Table 1. The criteria to identify conceptual knowledge (C).

\begin{tabular}{|l|l|}
\hline Score & Example from a student's KJS \\
\hline C1: Identification and definition of concepts & \\
\hline $\begin{array}{l}1-\text { at least one relevant general concept. The con- } \\
\text { cept is presented verbally, not as a letter symbol. }\end{array}$ & $\begin{array}{l}\text { "light", "particle", "energy", "radiation", "spec- } \\
\text { trum", "wave motion", "dualism", "field" }\end{array}$ \\
\hline $\begin{array}{l}2-\text { at least one relevant special concept or } \\
\text { presents a specification or limitation to mentioned } \\
\text { general concept. }\end{array}$ & $\begin{array}{l}\text { "ultraviolet light", "photon", "electron", "kinetic } \\
\text { energy", "wavelength", "scattering", "wave } \\
\text { behavior" }\end{array}$ \\
\hline $\begin{array}{l}\text { C2: Conditions for using a concept } \\
\text { one concept. There can be some inconsistency. A } \\
\text { possible relation between concepts is presented } \\
\text { verbally. }\end{array}$ & $\begin{array}{l}\text { "Classical physics is inconsistent with observa- } \\
\text { tions." } \\
\text { "There is a connection between the scattering } \\
\text { angle and the change in wavelength." }\end{array}$ \\
\hline $\begin{array}{l}2-\text { Presents a consistent limitation to usability of } \\
\text { at least one concept. }\end{array}$ & $\begin{array}{l}\text { "Energy is conserved." } \\
\text { "X-ray scattering from an electron is a quantum } \\
\text { phenomenon." } \\
\text { "Double-slit experiment confirms the wave and } \\
\text { particle nature of light." }\end{array}$ \\
\hline
\end{tabular}


Table 2. The criteria to identify relational knowledge $(R)$.

\begin{tabular}{|c|c|}
\hline Score & Example from a student's KJS \\
\hline \multicolumn{2}{|c|}{ R1: Identification and definition of relations and models } \\
\hline $\begin{array}{l}1-\text { at least one relation between relevant con- } \\
\text { cepts or a relevant model. There can be some } \\
\text { inconsistency. }\end{array}$ & $\begin{array}{l}\text { "Energy and frequency are proportional." } \\
\text { "according to Compton formula" } \\
\text { "quantization of electromagnetic radiation" } \\
\text { "A photon is a wave and a particle." } \\
\text { "Planck's quantum hypothesis" }\end{array}$ \\
\hline $\begin{array}{l}2-\text { a specification to a relation or explains } \\
\text { meaning or context of a model. }\end{array}$ & $\begin{array}{l}\text { "E = hf" } \\
\text { "Einstein predicted that an electron in a metal radi- } \\
\text { ated by light can receive energy from the radiation } \\
\text { only in discrete packages, quanta." }\end{array}$ \\
\hline \multicolumn{2}{|l|}{ R2: Conditions for using a relation or a model } \\
\hline $\begin{array}{l}1-\text { Reflects on limitations of a relation or a } \\
\text { model. There can be some inconsistency. }\end{array}$ & $\begin{array}{l}\text { "Classical model doesn't explain the studied phenom- } \\
\text { enon." } \\
\text { "The wave and the particle nature of light show in } \\
\text { different measurements." }\end{array}$ \\
\hline $\begin{array}{l}2-\text { Presents at least one consistent context or } \\
\text { limitation of a relation or model. }\end{array}$ & $\begin{array}{l}\text { "E = hf - W, where E is the maximum kinetic energy." } \\
\text { "This kind of quantum object passing through both } \\
\text { slits at the same time can be presented with fields." }\end{array}$ \\
\hline
\end{tabular}

Table 3. The criteria to identify strategic knowledge (S).

\begin{tabular}{|l|l|}
\hline Score & Example from a student's KJS \\
\hline S1: Identification and definition of experiments or their results \\
\hline $\begin{array}{l}1-\text { Mentions at least one relevant experiment } \\
\text { or a result from an experiment. There can be } \\
\text { some inconsistency. }\end{array}$ & $\begin{array}{l}\text { "Millikan's experiment on photoelectric effect" } \\
\text { "Electrons' escape from metal depends on the fre- } \\
\text { quency of radiation." }\end{array}$ \\
\hline $\begin{array}{l}2 \text { - Presents at least one relevant arrangement } \\
\text { for an experiment or a result from an experi- } \\
\text { ment. }\end{array}$ & $\begin{array}{l}\text { "Let's study how high a stopping potential is needed } \\
\text { to stop the motion of electrons released by radiating } \\
\text { certain wavelength (or to stop the current)." } \\
\text { "An interference pattern emerges in a double-slit } \\
\text { experiment, but not when a photon's path at the slit } \\
\text { is monitored." }\end{array}$ \\
\hline $\begin{array}{l}\text { S2: Conditions for using the experiment } \\
\text { tions of the experimental setup. There can be } \\
\text { some inconsistency. }\end{array}$ & \begin{tabular}{l} 
"is based on presumptions, which are accurate prob- \\
ably only with light elements" \\
\hline $\begin{array}{l}\text { experiment or presents consistent limitations of } \\
\text { the experimental setup. }\end{array}$
\end{tabular} \\
\hline
\end{tabular}




\section{RESULTS}

First, we inspect the average scores of all four KJSs. Conceptual knowledge (criteria C1 and C2) was mainly best presented in students' KJSs. Relational knowledge (criteria R1 and R2) was a little weaker and strategic knowledge (criteria S1 and S2) was the weakest. Combined average score of criteria 1 and 2 was 1.80 for conceptual knowledge, 1.56 for relational and 1.40 for strategic knowledge. Regarding conceptual knowledge, identification and definition of concepts (criterion C1) was mainly better presented than conditions for using them (criterion C2). With relational knowledge, a similar difference was detected but not as clearly. With strategic knowledge, there was no clear difference between criteria S1 and S2. (See Fig. 4)

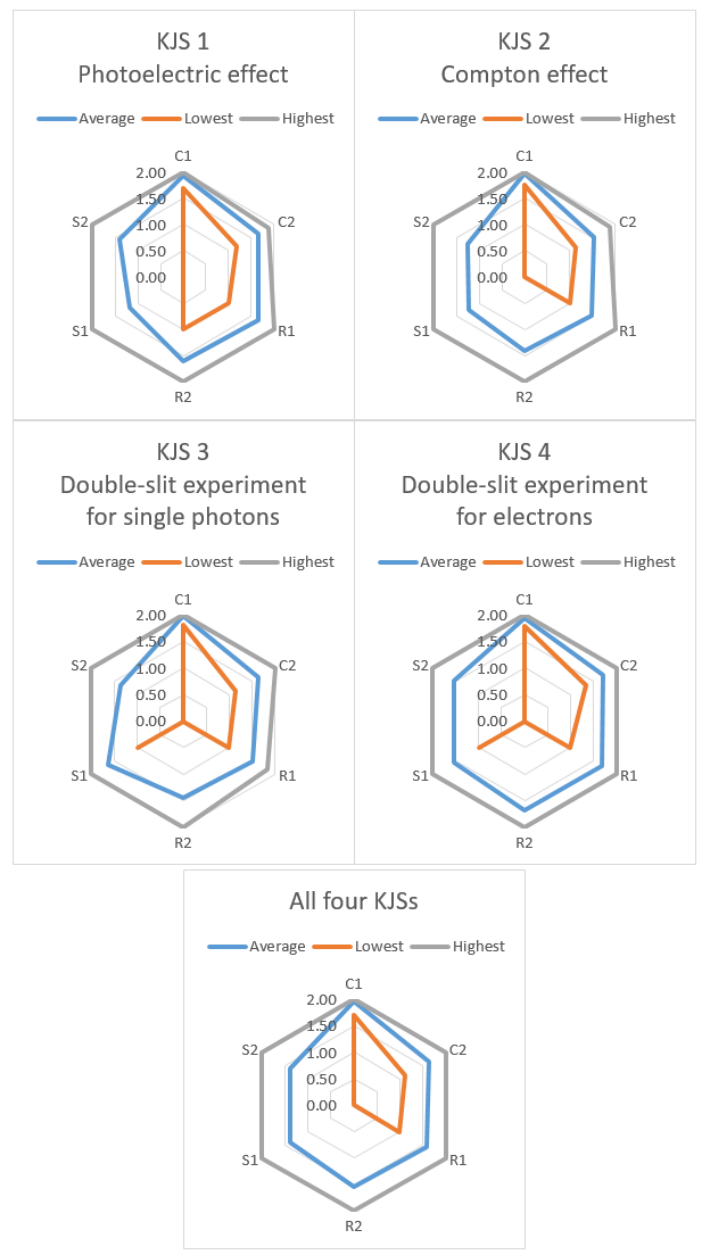

Figure 4. Average scores and ranges by KJSs and by criteria normalized between values o and 2. Criteria $C$ means conceptual, $R$ relational and $S$ strategic knowledge. $C 1, R 1$ and $S 1$ refer to identification and definition of relevant content, $C_{2}, R 2$ and $S 2$ refer to reflecting conditions for using them.

Identification and definition of relevant concepts (C1) scores were between 1.70 and 2.0o. Furthermore, $25 \%$ of all KJSs scored from 1.50 to 2.00 in every criteria (see an example in Fig. 5 ). Nine students $(\mathrm{N}=17)$ had at least one of these kinds of KJSs, but only one student (number 12, see Figure 7) succeeded in all KJSs. $35 \%$ of KJSs were successful in five criteria (scores 1.50-2.00 each) and 
poor in one (score under the average 1.5). 13 students had at least one KJS in this category. Weakest performance was usually either in identification of experiments and their results ( $\mathrm{S} 1)$ or in conditions for using an experiment (S2; see the first two KJSs in Fig. 5). We have explicated the application of the criteria C, R and S for two examples (students 1 and 6, for KJS 1) in Appendix A.

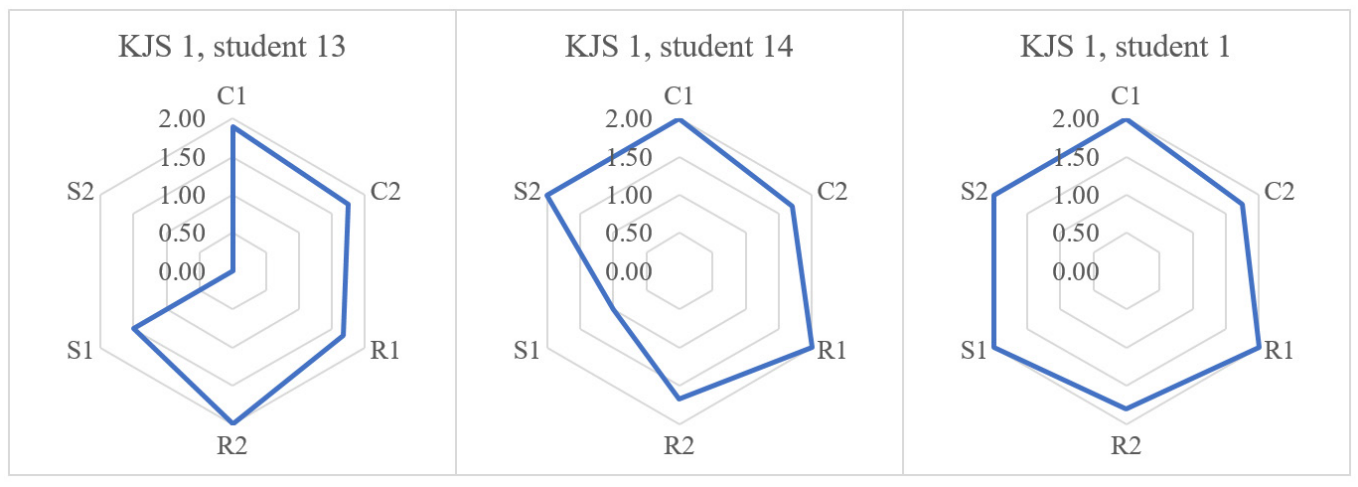

Figure 5. Examples of individual KJSs' scores where five criteria are successfully manifested (left and center) and all six criteria (right) presented.

There were also many other kinds of scores as seen in Fig. 6. For example, in the first KJS both strategic criterion S1 and S2 have scored o and in the second one criterion R2 is o. In the third task, only conceptual knowledge is well presented ( $\mathrm{C} 1$ and $\mathrm{C} 2$ over 1.50) and knowledge of conditions for using experiments (S2) is lacking completely. There was a big and heterogeneous set of KJSs with a mix of inadequate criteria: a certain combination of problems was found always only in 1-3 KJSs. $40 \%$ of KJSs were in this category. Of all students, 11 had at least one KJS like this and students 15 and 16 all four.

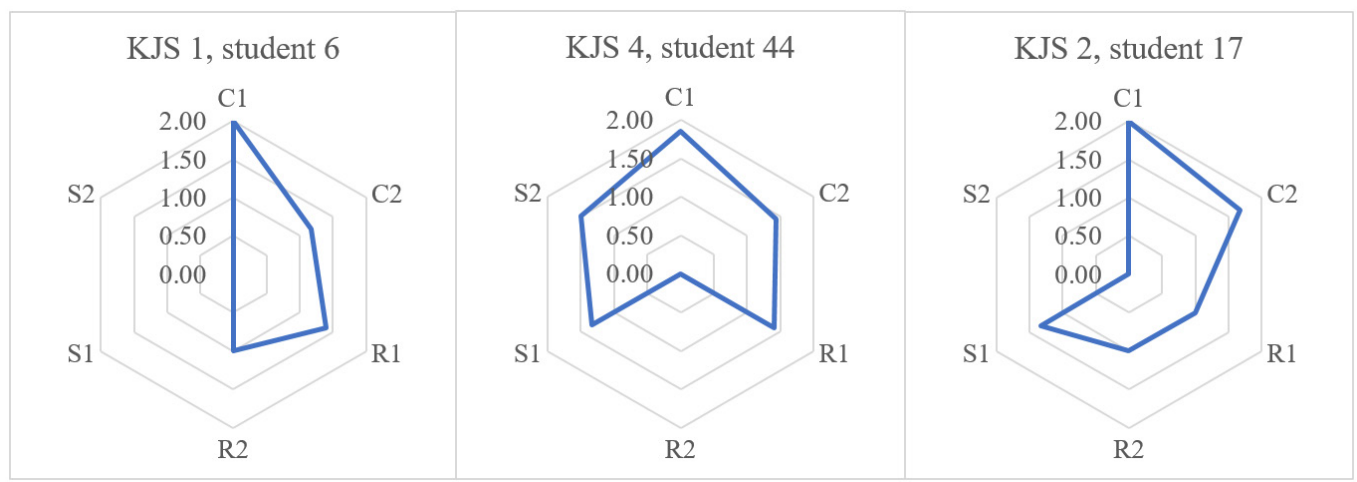

Figure 6. Examples of the great variation in individual KJSs' scores.

Individual students' KJSs divided into two categories: 1) all criteria were balanced in every four KJSs and 2) at least one criterion was significantly weaker than others in at least one of four KJSs.

Student's KJSs were categorized balanced if all their hexagonal score plots were convex by their shape and all the six criteria scored above 0 . A convex shape means the KJS has succeeded in all criteria in some level and especially there is no score o or other significantly lower score in any criteria com- 
pared to other criteria. Nine students $(1,3,4,5,7,10,12,14$, and 16) had only balanced KJSs. In Fig. 7 there are three examples of these kinds of scores.

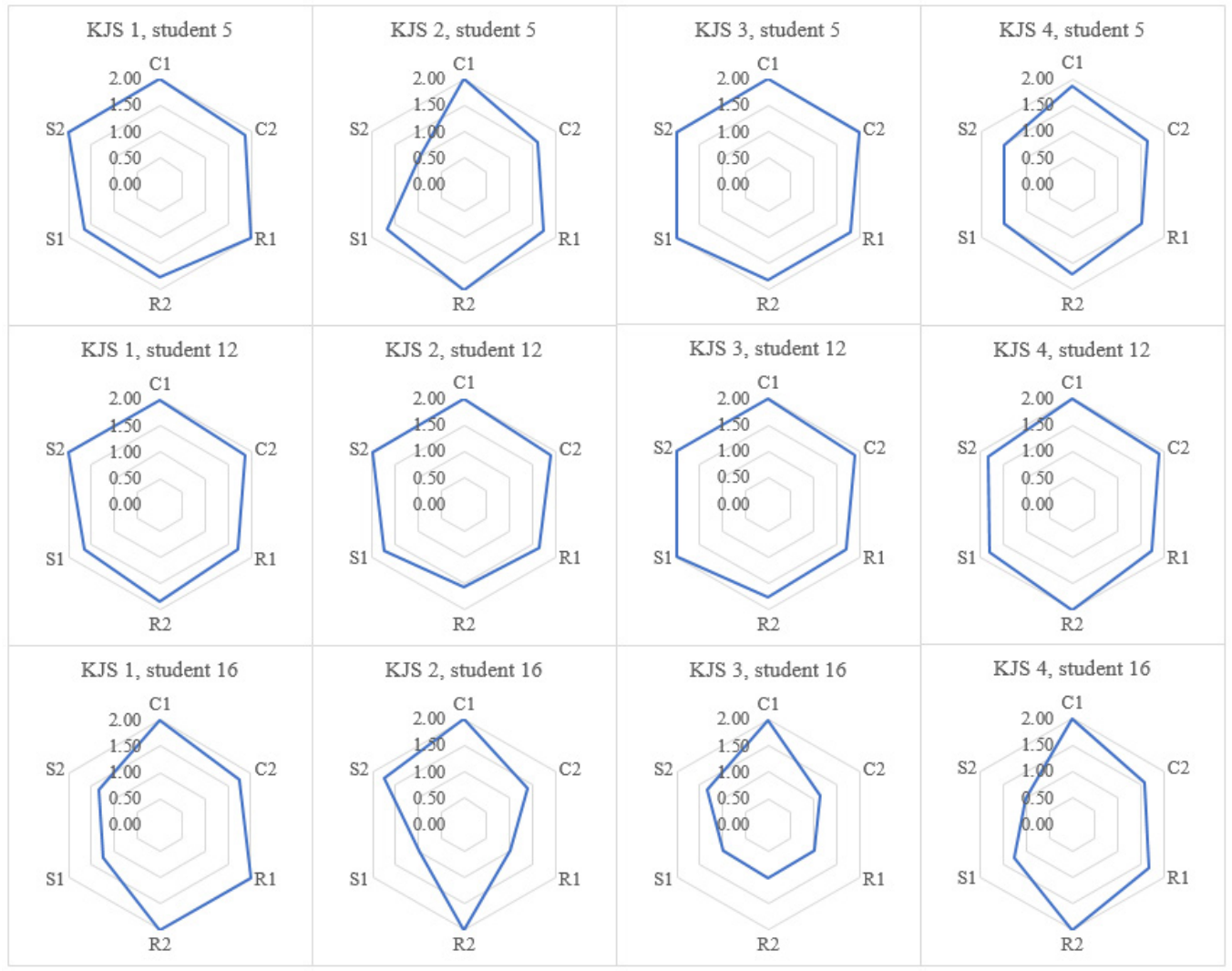

Figure 7. Three examples of student performances with balanced KJS scores. In one row, there are one individual student's all KJS's scores.

Fig. 8 presents examples of student performances with one or more unbalanced KJS. They all had at least one KJS with at least one criterion, which score was significantly lower than the others' were. This can be seen as a concave shape of the score plot or score o in some of the criteria (see also the first KJS in Fig. 6). Eight students' KJSs were in this unbalanced category (students 2, 6, 8, 9, 11, 13, 15 , and 17). What was conspicuous was that not one of these students had only similarly shaped score plots: strong and weak criteria varied depending on the task. Also, every student in this category had at least one KJS that had scored $\mathrm{o}$ in at least one criterion. 


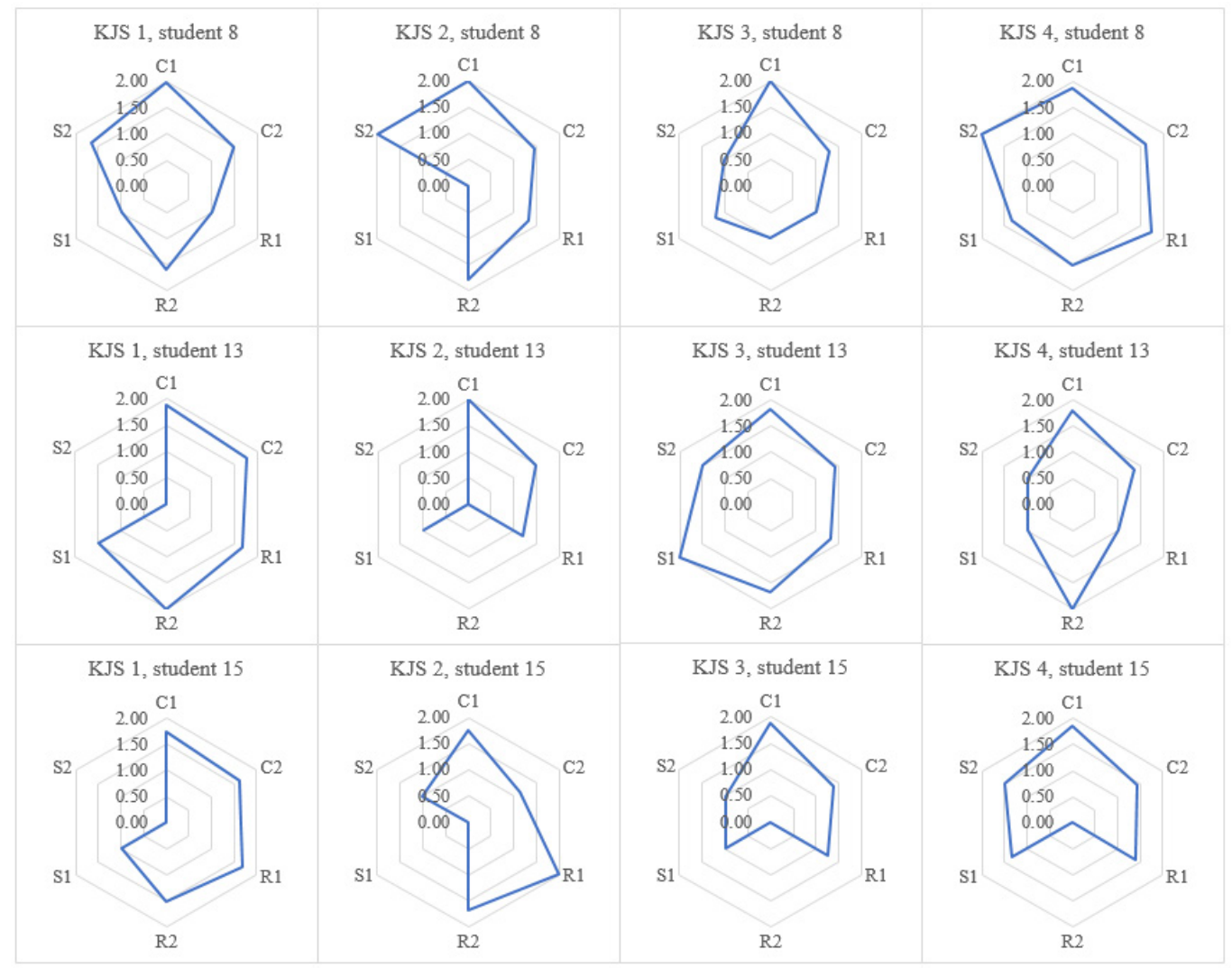

Figure 8. Three examples of student performances with unbalanced KJS scores. In one row, there are one student's all four KJS's scores.

In this sample, individual KJSs fell into these two categories quite easily. Students could be roughly divided into three categories according to their score balance and score level.

1. highest-scoring students $(1,3,5,10,12$, and 14) had only balanced KJSs.

2. lowest-scoring students $(2,6,8,13,15$, and 17$)$ had all unbalanced scores.

3. five students $(4,7,9,11$ and 16$)$ did not have such connection between score balance and score level.

\section{DISCUSSION AND CONCLUSIONS}

There is a growing stress to add argumentation, critical thinking and knowledge justification into high school and university teaching (Fischer et al., 2014; Holmes, Wieman \& Bonn, 2015; Rapanta et al., 2013, see also Turiman et al., 2012). Schools and educators play a key role when it comes to learning critical thinking and reasoning. Still, many teachers have difficulties in giving valid knowledge justification. This affects the whole teaching: the logical order of presented knowledge and soundness of reasoning are both essential parts of well-planned teaching (Mäntylä \& Nousiainen, 2014; Nousiainen, 2017). The demand for coherent and well-ordered subject matter knowledge is an important aim in subject teacher education (Nousiainen, 2017; see also Lachner \& Nückles, 2016)

We have here proposed how such themes can be applied into physics teacher education in fostering pre-service physics teachers' abilities to deliver coherent and consistent arguments in their future teaching. The analysis framework approaches physics content knowledge from the viewpoint of con- 
ceptual, relational and strategic knowledge. Results indicate that many students have room for enhancing their physics knowledge and ability to argue it. Even though different scores in criteria can lead to same overall score, the best-scored students performed balanced scores between all criteria. It seems that if one has great difficulties with some criterion, it is hard to compensate by succeeding with all others. It is notable that the analysis framework concentrated only on strengths in students' physics knowledge and omitted possible weaknesses. Nevertheless, the framework reveals significant variation between students' justifications.

Results shows that especially identification and definition of relevant conceptual knowledge is better known than reflecting its usability, limitations and context. This implies lack of an expert's coherent view of physics knowledge (Lachner \& Nückles, 2016). Lowest-scoring students had all unbalanced scores where strong and weak criteria varied depending on the task except criterion $\mathrm{C} 1$ which was always strong. Students know relevant concepts and when to use them but many lack an organized understanding of what else a good physics justification should include. As physics is often taught as established facts with no need of reasoning, students are not used to presenting strategic knowledge and should be enhanced in it (cf. Mäntylä \&Hämäläinen, 2015; Sandoval \& Millwood, 2007). There were also other issues pointing at unclear issues in regard the nature of scientific knowledge. Based on KJSs, many students seemed confused about general scientific concepts: for example, "phenomenon" and "model" had been mixed up with each other or used in otherwise wrong context in many KJSs.

The four articles were different from each other, for example in length (differing from 5 to 32 pages), use of experiments or modelling, straightforwardness and maybe how readable they were to someone not a native English-speaker nor used to read scientific articles. KJS 2 was the only one where both an experimental and theoretical side were needed and its average scores were the lowest. Apart from KJS 2 , the average scores rose very moderately during the course. However, to be able to discuss possible progression during the course, sample should be larger.

It remains unclear, whether the results tell more about mastering physics knowledge itself or perceiving its necessity in argumentation. Introductory quantum physics as KJSs' subject might be one of the hardest physics topics physics subject teachers possibly have to teach themselves. Challenges with the topic itself certainly can affect ability to construct a valid argument on it. Either way, students have studied these topics first in high school, then during basic-level university courses and now third time in the studied teacher preparation course. Despite of these studies, many pre-service teachers had fundamental problems with presenting the knowledge. Pre-service teachers' difficulties with physics content knowledge probably root in insufficient understanding during earlier basic studies in university (Mäntylä \& Nousiainen, 2014). Although basic contents of quantum physics are repeated, these reflective assignments such as KJSs might be the first time when students have had time to ponder their own thinking around the topic. Our results show that there is need and room for these kinds of practical tools which help future teachers to organize and consider their own knowledge. Our results did not show any progress in pre-service physics teachers' argumentation skills, probably due to small sample and difficult topic. However, we believe that these skills can be promoted with careful and patient use of this kind of reflective tool (c.f. Holmes, Wieman \& Bonn, 2015).

Difficulties in producing proper knowledge justification as shown with this analysis do not concern only teacher preparation courses and they cannot be solved only within them. Assignments promoting reflective thinking should be a part of basic studies and even school physics: with them, students' level of knowledge and possible gaps could be made visible to students themselves and teachers and it would be possible to proceed to required scaffolding on time. The results imply teaching both physics content knowledge, and presenting and arguing it are both worth investing in.

\section{FUNDING}

This research was funded by Academy of Finland through grant number 311449 . 


\section{APPENDIX A}

Table A1. One example (translated from Finnish) of a pre-service physics teacher's KJS on photoelectric effect (KJS 1, student 1, see Figure 3.) and its scores with a short rationale.

\begin{tabular}{|c|c|c|}
\hline Unit of analysis & Scores & Rationale \\
\hline $\begin{array}{l}\text { 1. Motive: Classical physics did not } \\
\text { explain photoelectric effect: electrons } \\
\text { should have been able to escape with } \\
\text { any frequency as long as intensity was } \\
\text { high enough, but this did not happen. }\end{array}$ & $\begin{array}{l}\text { C1: } 2 \\
\text { C2: } 1 \\
\text { R1: } 0 \\
\text { R2: } 1 \\
\text { S1: } 0 \\
\text { S2: } 0\end{array}$ & $\begin{array}{l}\text { C1: a special concept 'photoelectric effect' } \\
\text { C2: a limitation 'classical physics did not explain - - ' } \\
\text { R1: - } \\
\text { R2: a limitation 'classical physics did not explain } \\
\text { photoelectric effect' } \\
\text { S1: - } \\
\text { S2: - }\end{array}$ \\
\hline $\begin{array}{l}\text { 2. Previous theory: Planck had presented } \\
\text { quantum hypothesis linked with black- } \\
\text { body radiation, Einstein had predicted } \\
\text { quantization of energy } \mathrm{E}=\mathrm{hf} \text { in emission. }\end{array}$ & $\begin{array}{l}\text { C1: } 2 \\
\text { C2: } 2 \\
\text { R1: } 2 \\
\text { R2: } 2 \\
\text { S1: } 0 \\
\text { S2: } 0\end{array}$ & $\begin{array}{l}\text { C1: a special concept 'black-body radiation' } \\
\text { C2: a limitation to usability of a concept 'quantiza- } \\
\text { tion of energy' } \\
\text { R1: a relation 'E=hf' } \\
\text { R2: a context 'quantization of energy E=hf in emis- } \\
\text { sion' } \\
\text { S1: - } \\
\text { S2: - }\end{array}$ \\
\hline $\begin{array}{l}\text { 3. Phenomena: Hertz noticed UV-light } \\
\text { neutralizes a negatively charged elec- } \\
\text { troscope. When a light beam hits metal, } \\
\text { electrons escape as long as frequency } \\
\text { exceeds a threshold value. The intensity } \\
\text { of radiation doesn't increase kinetic } \\
\text { energy of electrons. }\end{array}$ & $\begin{array}{l}\text { C1: } 2 \\
\text { C2: } 2 \\
\text { R1: } 0 \\
\text { R2: } 0 \\
\text { S1: } 2 \\
\text { S2: } 0\end{array}$ & $\begin{array}{l}\text { C1: a special concept 'UV-light' } \\
\text { C2: a limitation to usability of a concept 'UV-light } \\
\text { neutralizes a negatively charged electroscope' } \\
\text { R1: - } \\
\text { R2: - } \\
\text { S1: a relevant experiment and result } \\
\text { S2: - }\end{array}$ \\
\hline $\begin{array}{l}\text { 4. Experiment and measurements: Light } \\
\text { from a mercury lamp was filtered mono- } \\
\text { chromatic and shot towards different } \\
\text { alkali metals with a complicated setup, } \\
\text { frequency and intensity were varied. } \\
\text { Escaping electrons moved to another } \\
\text { plate and caused an electric current, } \\
\text { and knowing the stopping voltage, we } \\
\text { can calculate the maximum energy of } \\
\text { electrons. }\end{array}$ & $\begin{array}{l}\text { C1: } 2 \\
\text { C2: } 2 \\
\text { R1: } 0 \\
\text { R2: } 0 \\
\text { S1: } 2 \\
\text { S2: } 0\end{array}$ & $\begin{array}{l}\text { C1: a special concept 'electron' } \\
\text { C2: a consistent limitation and context 'escaping } \\
\text { electrons - - caused an electric current' } \\
\text { R1: - } \\
\text { R2: - } \\
\text { S1: an arrangement for an experiment } \\
\text { S2: - }\end{array}$ \\
\hline $\begin{array}{l}\text { 5. Data model: Maximum energy is } E= \\
\text { hf }-F \text {, where } F \text { tells minimum energy } \\
\text { needed to work electrons loose. }\end{array}$ & $\begin{array}{l}\text { C1: } 2 \\
\text { C2: } 1 \\
\text { R1: } 2 \\
\text { R2: } 2 \\
\text { S1: } 0 \\
\text { S2: } 0\end{array}$ & $\begin{array}{l}\text { C1: a special concept 'electron' } \\
\text { C2: a limitation ' } F \text { tells minimum energy needed to } \\
\text { work electrons loose' } \\
\text { R1: a relation ' } E=h f-F \text { ' } \\
\text { R2: a limitation ' } F \text { tells minimum energy needed - -' } \\
\text { S1: - } \\
\text { S2: - }\end{array}$ \\
\hline $\begin{array}{l}\text { 6. Conclusion: Energy is quantized, there } \\
\text { is a minimum energy for electrons' } \\
\text { escape, and the escape depends on } \\
\text { frequency, not intensity. The experiment } \\
\text { refined the value of Planck constant } h= \\
6.57^{*} 10^{\wedge}-27 \text {. }\end{array}$ & $\begin{array}{l}\text { C1: } 2 \\
\text { C2: } 2 \\
\text { R1: } 2 \\
\text { R2: } 2 \\
\text { S1: } 0 \\
\text { S2: } 2\end{array}$ & $\begin{array}{l}\text { C1: a special concept 'electron' } \\
\text { C2: a limitation 'energy is quantized' } \\
\text { R1: a context of a model } \\
\text { R2: a context of a model } \\
\text { S1: - } \\
\text { S2: meaning of an experiment }\end{array}$ \\
\hline
\end{tabular}




\begin{tabular}{|c|c|c|}
\hline $\begin{array}{l}\text { 7. Qualification review: The experiment } \\
\text { was very accurate, with a } 0.5 \% \text { error. } \\
\text { When measurements were repeated, } \\
\text { the value of Planck constant was nearly } \\
\text { the same. This way measuring seems } \\
\text { to produce the most accurate value to } \\
\text { Planck constant. }\end{array}$ & $\begin{array}{l}\text { C1: } 2 \\
\text { C2: } 2 \\
\text { R1: } 0 \\
\text { R2: } 0 \\
\text { S1: } 0 \\
\text { S2: } 2\end{array}$ & $\begin{array}{l}\text { C1: a special concept 'Planck constant' } \\
\text { C2: a limitation ' } 0.5 \% \text { error' } \\
\text { R1: - } \\
\text { R2: - } \\
\text { S1: - } \\
\text { S2: limitations of an experiment }\end{array}$ \\
\hline $\begin{array}{l}\text { 8. Implication: The experiment showed } \\
\text { the quantization of energy and light's } \\
\text { wave and particle nature, at the same } \\
\text { time. The Einstein equation } E=h f-F \text { is } \\
\text { valid. }\end{array}$ & $\begin{array}{l}\text { C1: } 2 \\
\text { C2: } 2 \\
\text { R1: } 2 \\
\text { R2: } \\
\text { S1: } 0 \\
\text { S2: } 2\end{array}$ & $\begin{array}{l}\text { C1: a limitation to general concept 'quantization of } \\
\text { energy' } \\
\text { C2: a limitation 'quantization of energy' } \\
\text { R1: a relation ' } \mathrm{E}=\mathrm{hf}-\mathrm{F}^{\prime} \\
\mathrm{R} 2 \text { : a limitation and context } \\
\text { S1: - } \\
\text { S2: meaning of an experiment }\end{array}$ \\
\hline
\end{tabular}

Table A2. One example (translated from Finnish) of a pre-service physics teacher's KJS on photoelectric effect (KJS 1, student 6, see Figure 3) and its scores with a short rationale.

\begin{tabular}{|c|c|c|}
\hline Unit of analysis & Scores & Rationale \\
\hline $\begin{array}{l}\text { 1. To explain why emg-radiation works } \\
\text { electrons loose from metal surface }\end{array}$ & $\begin{array}{l}\text { C1: } 2 \\
\text { C2: } 1 \\
\text { R1: } 0 \\
\text { R2: } 0 \\
\text { S1: } 0 \\
\text { S2: } 0\end{array}$ & $\begin{array}{l}\text { C1: a special concept 'electron' } \\
\text { C2: a context 'radiation works electrons } \\
\text { loose' } \\
\text { R1: - } \\
\text { R2: - } \\
\text { S1: - } \\
\text { S2: - }\end{array}$ \\
\hline 2. The particle-like features of light & $\begin{array}{l}\text { C1: } 2 \\
\text { C2: } 1 \\
\text { R1: } 0 \\
\text { R2: } 0 \\
\text { S1: } 0 \\
\text { S2: } 0\end{array}$ & $\begin{array}{l}\text { C1: a specification to a general concept } \\
\text { C2: a limitation to a concept } \\
\text { R1: - } \\
\text { R2: - } \\
\text { S1: - } \\
\text { S2: - }\end{array}$ \\
\hline $\begin{array}{l}\text { 3. Planck's quantum theory on thermal } \\
\text { radiation }\end{array}$ & $\begin{array}{l}\text { C1: } 2 \\
\text { C2: } 1 \\
\text { R1: } 1 \\
\text { R2: } 1 \\
\text { S1: } 0 \\
\text { S2: } 0\end{array}$ & $\begin{array}{l}\text { C1: a special concept 'thermal radiation' } \\
\text { C2: a context of a concept } \\
\text { R1: a relevant model } \\
\text { R2: a limitation to a model } \\
\text { S1: - } \\
\text { S2: - }\end{array}$ \\
\hline $\begin{array}{l}\text { 4. The energy of a quantum proportion- } \\
\text { al to the frequency of radiation }\end{array}$ & $\begin{array}{l}\text { C1: } 2 \\
\text { C2: } 2 \\
\text { R1: } 1 \\
\text { R2: } 0 \\
\text { S1: } 0 \\
\text { S2: } 0\end{array}$ & $\begin{array}{l}\text { C1: a limitation to a concept } \\
\text { C2: a limitation to usability of a concept } \\
\text { R1: a relation } \\
\text { R2: - } \\
\text { S1: - } \\
\text { S2: - }\end{array}$ \\
\hline 5. $E=h f$ & $\begin{array}{l}\text { C1: } 0 \\
\text { C2: } 0 \\
\text { R1: } 2 \\
\text { R2: } 0 \\
\text { S1: } 0 \\
\text { S2: } 0\end{array}$ & $\begin{array}{l}\text { C1: - } \\
\text { C2: - } \\
\text { R1: a relation } \\
\text { R2: - } \\
\text { S1: - } \\
\text { S2: - }\end{array}$ \\
\hline
\end{tabular}




\begin{tabular}{|l|l|l|}
\hline 6. Electric charge is discharged from & C1: & C1: a special concept 'electric charge' \\
metal surface & C2: & C2: a context of a concept \\
& R1: 0 & R1: - \\
& R2: 0 & R2: - \\
& S1: 0 & S1: - \\
& S2: 0 & S2: - \\
\hline 7. Photoelectric effect, E=hf-W & C1: & C1: a special concept 'photoelectric effect' \\
& C2: 0 & C2: - \\
& R1: 2 & R1: a relation \\
& R2: 0 & R2: - \\
& S1: 0 & S1: - \\
& S2: 0 & S2: - \\
\hline 8. Restrictions? & C1: 0 & C1: - \\
& C2: 0 & C2: - \\
& R1: 0 & R1: - \\
& R2: 0 & R2: - \\
& S1: 0 & S1: - \\
& S2: 0 & S2: - \\
\hline 9. Wave-particle & C1: 2 & C1: a special concept 'wave-particle dualism' \\
dualism, & C2: 1 & C2: a limitation \\
introduction of & R1: 1 & R1: a relevant model 'wave-particle dualism' \\
quantum theory & R2: 0 & R2: - \\
& S1: 0 & S1: - \\
& S2: 0 & S2: - \\
\hline
\end{tabular}

\section{REFERENCES}

Compton, A. (1923a). A quantum theory of the scattering of X-rays by light elements. Physical Review, 21(5), 483-502.

Compton, A. (1923b). The spectrum of scattered X-rays. Physical Review, 22(5), 409-413.

Fischer, F., Kollar, I., Ufer, S., Sodian, B., Hussmann, H., Pekrun, R., . . Eberle, J. (2014). Scientific reasoning and argumentation: Advancing an interdisciplinary research agenda in education. Frontline Learning Research, 2(3), 28-45. doi:10.14786/flr.v2i2.96

Goldwater, M. B., \& Schalk, L. (2016). Relational categories as a bridge between cognitive and educational research. Psychological Bulletin, 142(7), 729-757. doi:10.1037/bulooooo43

Halford, G. S., Wilson, W. H., \& Phillips, S. (2010). Relational knowledge: The foundation of higher cognition. Trends in Cognitive Sciences, 14(11), 497-505. doi:10.1016/j. tics.2010.08.005

Halloun, I. (2007). Mediated modeling in science education. Science \& Education, 16, 653-697. doi:10.1007/s11191-006-9004-3

Hobson, A. (2012). There are no particles, there are only fields. American Journal of Physics, 81, 211-223. doi:10.1119/1.4789885

Holmes, N. G., Wieman, C. E., \& Bonn, D. A. (2015). Teaching critical thinking. Proceedings of the National Academy of Sciences, 112(36), 11199-11204.

Hyytinen, H., Löfström, E., \& Lindblom-Ylänne, S. (2017). Challenges in argumentation and paraphrasing among beginning student in educational sciences. Scandinavian Journal of Educational Research, 61(4), 411-429. doi:10.1080/00313831.2016.1147072

Kokkonen, T. (2017). Models as relational categories. Science \& Education, 26(7-9) doi:10.1007/s11191-017-9928-9 
Koponen, I. T. (2007). Models and modelling in physics education: A critical re-analysis of philosophical underpinnings and suggestions for revisions. Science \& Education, 16(7-8), 751-773. doi:10.1007/s11191-006-9000-7

Koponen, I. T., \& Kokkonen, T. (2014). A systemic view of the learning and differentiation of scientific concepts: The case of electric current and voltage revisited. Frontline Learning Research, 2(3), 140-166. doi:10.14786/flr.v2i2.120

Kosso, P. (2009). The large-scale structure of scientific method. Science \& Education, 18(1), 33-42. doi:10.1007/s11191-008-9143-9

Kuhn, T. S. (2000). The road since structure. Chicago: University of Chicago Press.

Lachner, A., \& Nückles, M. (2015). Bothered by abstractness or engaged by cohesion? experts' explanations enhance novices' deep-learning. Journal of Experimental Psychology: Applied, 21(1), 101-115. doi:10.1037/xapooooo38

Lachner, A., \& Nückles, M. (2016). Tell me why! content knowledge predicts process-orientation of math researchers' and math teachers' explanations. Instructional Science, 44(3), 221-242. doi:10.1007/s11251-015-9365-6

Mäntylä, T., \& Hämäläinen, A. (2015). Obtaining laws through quantifying experiments: Justifications of pre-service physics teachers in the case of electric current, voltage and resistance. Science \& Education, 24(5-6), 699-723. doi:10.1007/s11191-015-9752-z

Mäntylä, T. and Nousiainen, M. (2014). Consolidating Pre-service Physics Teachers' Subject Matter Knowledge Using Didactical Reconstructions. Science \& Education, 23(8), 1583-1604.

Millikan, R. (1916). A direct photoelectric determination of Planck's h. Physical Review, 7(3), 355-399. doi:10.1103/PhysRev.7.355

Nousiainen, M. (2013). Coherence of pre-service physics teachers' views of the relatedness of physics concepts. Science \& Education, 22(3), 505-525.

Nousiainen, M. (2017). Organization of Physics Content Knowledge for Teaching Purposes: From Knowledge Justification Schemes to Didactical Schemes. European Journal of Science and Mathematics Education, 5(2), 210-209.

Nousiainen, M., Hyytinen, H., Palmgren, E. \& Toom, A. (2019) How do physics teacher candidates substantiate their knowledge? An analytical framework for examining the epistemic dimensions of content knowledge in higher education. Education Sciences, 9(2), 120.

Rapanta, C., Garcia-Mila, M., \& Gilabert, S. (2013). What is meant by argumentative competence? an integrative review of methods of analysis and assessment in education. Review of Educational Research, 83(4), 483-520. doi:10.3102/0034654313487606

Rueckner, W., \& Titcomb, P. (1996). A lecture demonstration of single photon interference. American Journal of Physics, 64(2), 184-188. doi:10.1119/1.18302

Sandoval, W. A., \& Millwood, K. A. (2007). What can argumentation tell us about epistemology?.\&nbsp; In S. Erduran, \& M. P. Jiménez-Aleixandre (Eds.), Argumentation in science education (pp. 71-88). Dordrecht: Springer.

Shavelson, R. J. (2010). Measuring college learning responsibly: Accountability in a new era. Stanford, CA: Stanford University Press.

Shehab, H. M., \& Nussbaum, E. M. (2015). Cognitive load of critical thinking strategies. Learning and Instruction, 35, 51-61. doi://doi.org/10.1016/j.learninstruc.2014.09.004

Toulmin, S. E. (2003). The uses of argument. Cambridge: Cambridge university press.

Turiman, P., Omar, J., Daud, A. M., \& Osman, K. (2012). Fostering the 21st century skills through scientific literacy and science process skills. Procedia - Social and Behavioral Sciences, 59, 110-116. doi://doi.org/10.1016/j.sbspro.2012.09.253 